\title{
Central congenital hypothyroidism
}

INSERM

\section{Source}

INSERM. (1999). Orphanet: an online rare disease and orphan drug data base. Central congenital hypothyroidism. ORPHA:226298

Central or secondary congenital hypothyroidism is a type of permanent congenital hypothyroidism (see this term) characterized by permanent thyroid hormone deficiency that is present from birth and secondary to a disorder in the thyroid-stimulating hormone (TSH) - thyrotropin-releasing hormone (TRH) system. 